Research Article

\title{
Evolutionary Game of Government Subsidy Strategy for Prefabricated Buildings Based on Prospect Theory
}

\author{
Yu Liu $\left(\mathbb{D}\right.$, Dong Cai $\mathbb{D}^{D}$, Chunxiang Guo $\mathbb{D}$, and Haizhen Huang $\mathbb{D}$ \\ School of Business, Sichuan University, Chengdu 610065, China \\ Correspondence should be addressed to Dong Cai; caidong3@sina.com
}

Received 18 September 2020; Revised 4 November 2020; Accepted 12 November 2020; Published 28 November 2020

Academic Editor: Emilio Jiménez Macías

Copyright $\odot 2020 \mathrm{Yu}$ Liu et al. This is an open access article distributed under the Creative Commons Attribution License, which permits unrestricted use, distribution, and reproduction in any medium, provided the original work is properly cited.

\begin{abstract}
Based on the prospect theory, this paper establishes an evolutionary game model of government and construction units for the problem of poor subsidy construction of government-subsidized construction units and uses the replication dynamic equation to analyse the strategic choice of evolutionary games. The research shows that the evolutionary game system of the construction unit and the government cannot meet the government incentives, and the construction unit also adopts the stable state of the prefabricated building. In the long run, the government subsidy cannot determine whether or not the construction unit will adopt the prefabricated building, and it is the construction cost of the prefabricated building that determines. Therefore, the government's work should shift from subsidies to targeted incentives forconstruction units to reduce the cost of construction of prefabricated buildings. The unit levies an environmental tax and appropriately restricts the income from the traditional cast-inplace construction units, and, on the other hand, it increases the popularization of low-carbon and environmental protection of the fabricated buildings, so that more consumers can recognize the environmental benefits brought by the assembled buildings. It provides a reference for the government to promote the development of prefabricated buildings.
\end{abstract}

\section{Introduction}

Compared with the traditional construction method, the prefabricated building can achieve reduction or savings of about $70 \%, 60 \%, 55 \%, 25 \%$, and $20 \%$ in construction waste, wood template, plastering mortar, construction water, and construction energy consumption, respectively [1]. It has great practical significance for realizing the sustainable development of the construction industry and promoting the process of new urbanization. According to the requirements of the State Council and the Ministry of Housing and Urban-Rural Development, by 2026, China's prefabricated buildings will account for $30 \%$ of new buildings [2]. However, due to the imperfect standard system of prefabricated building standards in China, insufficient integrated design capability, and low-scale production efficiency, its production cost is high. According to relevant calculations, the incremental cost of the total cost of fabricated construction projects is about $260 \mathrm{yuan} / \mathrm{m}^{2}$ [3], the construction unit is more resistant to the high cost of prefabricated buildings, and consumers are not willing to pay for this, restricting the prefabricated buildings' promotion and application in China.

To this end, the central government and local governments have introduced policies such as land, fiscal and taxation, and construction area incentives at the national and local levels to support the development of prefabricated buildings. For example, since 2017, Beijing will grant construction area and financial incentives for qualified construction projects that meet the requirements; for parts and component manufacturers that meet the new wall material catalogue, they can enjoy the value-added tax (VAT) refund policy as required. Financial institutions are encouraged to increase credit support for prefabricated construction projects; at the same time, in the construction industry related evaluation awards, the index requirements for fabricated buildings are increased $[4,5]$. However, these subsidy policies have not promoted the development of prefabricated buildings in China. In 2017, the cumulative construction of prefabricated buildings in China was about 
150 million square meters, accounting for $8.4 \%$ of the newly started construction area, with countries and regions. The target values are far apart [6]. In order to analyse the effectiveness of the policy, Liu et al. [7] used content analysis to measure and analyse the policy tools used in China's existing fabricated building policy texts. It is pointed out that environmental and supply-oriented macro-policy tools are overexploited, and specific policy tools for construction units and research institutions are missing. Therefore, from the perspective of the government, considering the specific decision-making process of the construction unit, whether the existing subsidy policy can continue to promote the construction unit to adopt the prefabricated building, what should be subsidized in the end, and what factors affecting the construction unit adopting the prefabricated building are all urgent, clear, and important issues.

Most of the current construction methods are still traditional construction methods. If you want to switch from traditional construction to assembly construction, the construction unit should pay attention not only to the profit brought by the assembly construction method but also to the traditional construction method before making the decision. The profit obtained is a reference point to measure the economic benefits brought by the use of prefabricated construction. If the profit from the prefabricated construction method is lower than the traditional construction method, the psychological perception of the construction unit is loss. Only when the profit of the assembly construction method is higher than the traditional construction method, the psychological perception of the construction unit is obtained. At the same time, in the context of the current economic situation facing many challenges, construction unit decision makers are more cautious about controlling investment risks. More and more investors are inconsistent in their risk appetite in the face of gains and losses, becoming risk-seeking in the face of losses and showing risk aversion in the face of gains $[8,9]$. The behaviour of construction unit decision makers can be described by prospect theory. Prospect theory is widely used to describe the perceived bias of decision makers [10]. Combined with the reality of the construction unit, it is suitable for solving the decision-making problem of whether the construction unit considers whether to adopt the prefabricated building under the government subsidy environment.

Evolutionary games take groups as research objects, and it is not strictly required that game groups are completely rational. The replication dynamic equation and evolutionary stability strategies are two important concepts [11]. The replication dynamic equation describes the growth rate of a strategy in a population, that is, the difference between the fitness value and the average fitness value when the strategy is selected. It is a dynamic differential equation. According to this, it can be known that when the benefit obtained by selecting a strategy is higher than the average income of the group, the group of this strategy can be imitated in the entire group. Since replication dynamic equation can not only effectively describe the mutual transformation between game populations and the dynamic adjustment of their behaviours, but also reflect the domain stability of the steady state behaviour of the population, this paper will choose to replicate the dynamic equations to analyse the model [12].

In view of the practical problems of promoting the subsidy policy of prefabricated buildings, combined with the existing policies, the lack of consideration of the specific profit of the construction unit and the behaviour of the decision-making process, and the application of prospect theory to describe the decision-making process of the construction unit, this paper will be the foreground theory. Introduced into the process of evolutionary game analysis, establish the evolutionary game model of government and construction units, use the replication dynamic equation to analyse the strategic choice of evolutionary game, and provide countermeasures and suggestions for government subsidized assembly buildings.

The framework of this study is arranged as follows: Section 2 introduces the literature review of the paper, which includes three aspects: government subsidies, prospect theory, and evolutionary games. Section 3 is the hypothesis and building of the evolutionary game model for governments and units. Section 4 presents the analysis of the evolutionary model. Section 5 analyses the results derived from the evolutionary model.Section 6 is the numerical simulation of the model. The paper is concluded in the last section.

\section{Literature Review}

2.1. Government Subsidy. In fact, government subsidy has been the focus of scholarly research. For instance, Zhao et al. [13] developed a decision-making model considering both consumers' preference for remanufactured products and effect of the government subsidy and found that the optimal price and the subsidy-sharing percentage are inversely proportional to the weighted-sum of the price elasticity of demand. He et al. [14] explored channel structure and pricing decisions for the manufacturer and government's subsidy policy with competing new and remanufactured products. They found that government can encourage the manufacturer to adopt the desired channel structures by setting appropriate subsidy levels. Furthermore, higher subsidy level always benefits consumers and the whole supply chain, but not always so to the environment. In addition, some scholars have studied how the government should subsidize prefabricated buildings. For example, Chen et al. [15] used evolutionary game theory from the demand side and supply side of fabricated building development in order to solve the problem of poor incentive effect and explain how to design the incentive mechanism for the development of prefabricated buildings. It points out that the government guides developers to build prefabricated buildings through subsidies, market mechanisms, and interventions, prompting consumers to pay attention to and participate in the transformation of the construction industry and can achieve a win-win situation for the three parties. Chen et al. [16] established a government subsidy model under the condition of asymmetric information and complete information. The results show that the benefits 
brought by the subsidy policy to the government are affected by the construction cost, the payment of the end user and the developer's preference for green buildings, and other factors. These papers examine the effectiveness of government subsidized assembly buildings from the perspective of supply chain and information sharing and give relevant qualitative recommendations. However, the rationality and effectiveness of subsidized government are not investigated according to the specific expected profits of the construction unit in the decision-making process and the different behaviours caused by different expected profits, which is inconsistent with the reality.

2.2. Prospect Theory. Prospect theory is widely used to describe and predict the decision-making process when people are facing risks. For example, Shen et al. [17, 18], based on prospect theory, proposed an evolutionary game model involving building materials contractors and manufacturers. Polach et al. [19-21] introduced the extension of the foreground theory into an agent-based asset pricing model to study the loss avoidance phenomenon in risk aversion and loss-asymmetry processing. Chen et al. [22] constructed a short-life product supply chain centralized decision-making and contract coordination model considering strategic customer behaviour under the perspective of rational expectation utility theory and prospect theory and studied the different perspectives of rational expectation utility theory and perspective theory, whereas Zhao et al. [23, 24] introduced the prospect theory in the dynamic evolution of behavioural decision-making in the public sector and private sector during the process of portraying the risk management of major infrastructure projects. The prospect theory has great value as a descriptive model for decision making under risk and has a wide range of applications. The construction unit's behavioural decision actually belongs to the risk decision, and the choice of its behavioural strategy is based on its own subjective perception of the value of the strategy, rather than the actual utility of the strategy situation. Therefore, the construction unit's perception of value is consistent with the features of prospect theory.

2.3. Evolutionary Games. Evolutionary gaming has been a hot topic of scholarly research. For example, He et al. [25] used an evolutionary game model to study the choice between a traditional tourism strategy and a green tourism innovation strategy for two competing tourism operators. They found that the findings suggest that, under certain conditions, the green tourism innovation pioneer can monopolize the market. In addition, to be more efficient, governments first provide green subsidies to competitive tourist locations and/or more innovative service terms. He et al. [26] explored effective green incentives for governments to develop traditional tourism into green tourism by developing a dynamic evolutionary game model between governments, tourism firms, and tourists and suggested that governments first implement green incentives in areas with relatively small tourism markets. Many other scholars have studied evolutionary gaming issues related to government.
For instance, Mahmoudi et al. [27] modelled the comparison of government and producer objectives under different scenarios using two group evolutionary game theory approaches. The results show that government policies significantly affect producer activities, competitive markets, and emissions. The imposition of tariffs is the most effective way for governments to minimize environmental impacts. Sun et al. [28] used evolutionary game models to study the green investment strategies of manufacturers and material suppliers under a two-tier supply chain. The study found that changes in the green investment input-output ratio or government subsidies of suppliers and manufacturers would lead to the system evolving into a different evolutionary stability strategy. Setting the value of government subsidies in the appropriate range can reduce the freeriding behavior of suppliers or manufacturers in the market. The evolutionary game can be a good way to study the change and stability of government and construction unit strategies, which is the basis of the model studied in this paper.

\section{Evolutionary Game Model of Government and Construction Units}

\subsection{Model Hypothesis}

(1) The main body of the game is the government group and the construction unit group. The government is a rational group and the construction unit is an incomplete rational group. In the course of multiple games, it constantly seeks the optimal strategy. Therefore, the government's choice of strategy is based on the direct profit and loss of the strategy itself, while the construction unit's choice of strategy is based on its perception of the value of the strategy's payment. The prospect theory proposed by Kahneman and Tveraky in the 1970s was introduced into the game model. For certain losses and benefits, the player does not have deviations in perceived value and actual utility. When the players are uncertain about gains or losses, perceived utility and actual utility diverge. Assume the perceived utility of the construction unit is $v(\Delta \pi)$ [10, 29-33]:

$$
v(\Delta \pi)= \begin{cases}\Delta \pi^{\alpha}, & \Delta \pi \geq 0 \\ -\lambda(-\Delta \pi)^{\beta}, & \Delta \pi<0\end{cases}
$$

$\Delta \pi$ indicates the difference between the payment value of the construction unit and the value of the reference point, $\alpha$ represents the risk attitude coefficient obtained by the construction unit, $\beta$ represents the risk attitude coefficient for the construction unit perceived as loss, and $\lambda$ represents the sensitive coefficient for loss to income.

(2) Behavioral strategy and probability of adoption: the government's strategy is "incentives" and "no 
incentives," and the corresponding probabilities are $x$ and $1-x$. The strategy of the construction unit is "adopted" and "not adopted," and the corresponding probabilities are $y$ and $1-y$. The game strategy combination of both parties can be expressed in Table 1.

(3) Before the game between the two sides, the government does not encourage the construction unit to adopt the prefabricated building, and the construction unit does not use the prefabricated building. When the construction unit adopts the prefabricated building, the initial state of (no incentive, no adoption) is used as the reference point for decision-making. The government also uses the initial state of (no incentives, no adoption) to measure the incentives for construction units to use the benefits of prefabricated buildings. The revenue perception matrix of the government and the construction unit are shown in Table 2.

It can be known from the foreground theory that the two sides of the game have no deviation between the perceived value and the actual utility of the determined loss or benefit. Only when the two parties are uncertain about the cost and benefit, that is, the construction unit chooses to adopt the prefabricated building, the psychological perception utility will be produced. If $\Delta \pi=\left(a_{2}+a_{3}-a_{4}\right)-\left(a_{1}\right), \Delta \pi \geq 0$, the perception of the construction unit is to be obtained; when $\Delta \pi<0$, the perception of the construction unit is loss.

Refer to the existing literature to describe the relevant parameters in the establishment of the relevant model of the fabricated building [34]; the main parameters and interpretations referred to in this paper are shown in Table 3.

3.2. Model Building. Suppose when the government encourages the construction unit to use the assembled building the expected return is $U_{\mathrm{GY}}$, when the government does not encourage the construction unit to use the prefabricated building the expected income is $U_{\mathrm{GN}}$, the average expected return of the government is $\overline{U_{G}}$, there is the conclusion:

$$
\begin{aligned}
U_{\mathrm{GY}} & =y\left(b_{2}+b_{3}-b_{4}-b_{1}\right)+(1-y)\left(a_{5}-b_{4}\right), \\
U_{\mathrm{GN}} & =y\left(b_{2}+b_{3}-b_{1}\right), \\
\overline{U_{G}} & =x U_{\mathrm{GY}}+(1-x) U_{\mathrm{GN}} .
\end{aligned}
$$

According to the Malthusian equation [35], the government chooses the "incentive" strategy growth rate to be described by the difference between $U_{\mathrm{GY}}$ and $\bar{U}_{G}$. Let $t$ be the evolution time; the government's replication dynamic equation for the "incentive" strategy is

$$
\dot{x}=\frac{\mathrm{d} x}{\mathrm{~d} t}=x\left(U_{\mathrm{GY}}-\overline{U_{G}}\right)=x(1-x)\left(a_{5}-b_{4}-y a_{5}\right) .
$$

In the same way, the expected income when the construction unit adopts the assembled building is $U_{\mathrm{CY}}$, the expected return when the construction unit does not adopt the prefabricated building is $U_{\mathrm{CN}}$, and the average expected return of the construction unit is $\overline{U_{C}}$, there is the conclusion:

$$
\begin{aligned}
U_{\mathrm{CY}} & =x b_{4}+v(\Delta \pi), \\
U_{\mathrm{CN}} & =x\left(b_{4}-a_{5}\right), \\
\overline{U_{C}} & =y U_{\mathrm{CY}}+(1-y) U_{\mathrm{CN}} .
\end{aligned}
$$

The construction unit can choose the replication dynamic equation of the "adoption" strategy:

$$
\dot{y}=\frac{\mathrm{d} y}{\mathrm{~d} t}=y\left(U_{\mathrm{as}}-\overline{U_{C}}\right)=y(1-y)\left[x a_{5}+v(\Delta \pi)\right] .
$$

According to equations (3) and (5), a replica power system is available:

$$
\left\{\begin{array}{l}
\dot{x}=x(1-x)\left(a_{5}-b_{4}-y a_{5}\right), \\
\dot{y}=y(1-y)\left[x a_{5}+v(\Delta \pi)\right] .
\end{array}\right.
$$

Equation (6) depicts the evolutionary mechanism of the dynamic game of the interest subject of the governmentsubsidized strategy of the prefabricated building based on the foreground theory. $\Delta \pi=\left(a_{2}+a_{3}-a_{4}\right)-\left(a_{1}\right)$. Obviously, formula (6) does not include the net income of the government when the construction unit chooses the traditional cast-in-place construction and the direct economic benefits and indirect benefits of the government when the construction unit chooses the prefabricated building. The income from the government in formula (6) is the subsidy cost paid by the government when the construction unit chooses the prefabricated building, that is, the subsidy paid to the construction unit when the government encourages it.

\section{Analysis of the Model}

For ease of analysis, make $x^{*}=-(v(\Delta \pi)) / a_{5}$, $y^{*}=\left(a_{5}-b_{4}\right) / a_{5}$. Further analysis of equation (6) yields the following proposition:

Proposition 1. The equilibrium points of the replication power system are $O(0,0), A(1,0), B(0,1), C(1,1)$, when $0>v(\Delta \pi)>-a_{5}, a_{5}>b_{4} ; D\left(x^{*}, y^{*}\right)$ also is a point of equilibrium.

Proof. For equation (6), let $\bar{x}=0, \bar{y}=0$, get the equilibrium point of the system $O(0,0), A(1,0), B(0,1), C(1,1)$, when $0>v(\Delta \pi)>-a_{5}, a_{5}>b_{4}, \quad x^{*} \in(0,1), y^{*} \in(0,1), \quad$ and $\bar{x}=0, \bar{y}=0$, so $\left(x^{*}, y^{*}\right)$ also is a point of equilibrium.

However, the equilibrium point is not necessarily the evolutionary stability point of the system. The evolutionary stability point can be based on the method proposed by Friedman [36]: the Jacobi matrix of the replicating dynamic equation (6) is used to determine its local stable equilibrium: 
TABLE 1: Combination of strategy choices.

\begin{tabular}{lccc}
\hline Two sides of the game & \multicolumn{2}{c}{ Construction unit } \\
& & Adopt $y$ & No adoption $1-y$ \\
\hline Government & $\begin{array}{c}\text { Construction unit } x \\
\text { No incentive } 1-x\end{array}$ & (Incentive, adopt) & (Incentive, no adoption) \\
& (No incentive, adopt) & (No incentive, no adoption) \\
\hline
\end{tabular}

TABLE 2: Combination of strategy choices.

\begin{tabular}{lcc}
\hline Game strategy & Government & Construction unit \\
\hline (Incentive, apply) & $b_{2}+b_{3}-b_{4}-b_{1}$ & $b_{4}+v(\Delta \pi)$ \\
(No incentive, apply) & $b_{2}+b_{3}-b_{1}$ & $v(\Delta \pi)$ \\
(Incentive, no application) & $a_{5}-b_{4}$ & $b_{4}-a_{5}$ \\
(No incentive, no application) & 0 & 0 \\
\hline
\end{tabular}

TABLE 3: Summary of the main parameters involved in this article.

\begin{tabular}{|c|c|}
\hline Symbol & Interpretation \\
\hline$a_{1}$ & Net income when the construction unit chooses traditional cast-in-place construction \\
\hline$a_{2}$ & Direct economic benefits when the construction unit chooses a prefabricated building \\
\hline$a_{3}$ & Indirect benefits (such as corporate image, brand value) when the construction unit chooses a prefabricated building \\
\hline$a_{4}$ & The cost of the construction unit when choosing a prefabricated building \\
\hline$a_{5}$ & Fines imposed by the construction unit for failing to implement the government incentive policy \\
\hline$b_{1}$ & The government's net income when the construction unit chooses traditional cast-in-place buildings \\
\hline$b_{2}$ & Direct economic benefits of the government when the construction unit chooses a prefabricated building \\
\hline$b_{3}$ & $\begin{array}{l}\text { When the construction unit chooses a prefabricated building, the government's indirect benefits (resource conservation, } \\
\text { environmental protection, etc.) }\end{array}$ \\
\hline$b_{4}$ & The subsidy cost paid by the government when the construction unit chooses the prefabricated building \\
\hline
\end{tabular}
All parameters in the table are positive.

$$
J=\left[\begin{array}{ll}
\frac{\partial \dot{x}}{\partial x} & \frac{\partial \dot{x}}{\partial y} \\
\frac{\partial \dot{y}}{\partial x} & \frac{\partial \dot{y}}{\partial y}
\end{array}\right]=\left[\begin{array}{ll}
a_{11} & a_{12} \\
a_{21} & a_{22}
\end{array}\right]
$$

If the equilibrium point satisfies the determinant of the matrix $\operatorname{det} J=a_{11} a_{22}-a_{12} a_{21}>0$, and $\operatorname{tr} J=a_{11}+a_{22}<0$, the strategy represented by this point is the stable equilibrium of the system.

\section{Proposition 2}

(1) If $v(\Delta \pi)<0, a_{5}-b_{4}<0$, the stable equilibrium of the system is (no incentive, no adoption).

(2) If $b_{4}<a_{5}<-v(\Delta \pi)$, the stable equilibrium of the system is (incentive, no adoption).

(3) If $b_{4}>v(\Delta \pi) \geq 0$, the stable equilibrium of the system is (no incentive, adopt).

Proof. Get the Jacobian matrix [17] of the system according to equation (6):

$$
\begin{aligned}
J= & {\left[\begin{array}{cc}
(1-2 x)\left(a_{5}-b_{4}-y a_{5}\right), & -a_{5} x(1-x), \\
a_{5} y(1-y), & (1-2 y)\left[x a_{5}+v(\Delta \pi)\right],
\end{array}\right] } \\
\operatorname{det} J= & (1-2 x)\left(a_{5}-b_{4}-y a_{5}\right)(1-2 y)\left[x a_{5}+v(\Delta \pi)\right] \\
& +a_{5} x(1-x) a_{5} y(1-y), \\
\operatorname{tr} J= & (1-2 x)\left(a_{5}-b_{4}-y a_{5}\right)+(1-2 y)\left[x a_{5}+v(\Delta \pi)\right] .
\end{aligned}
$$

Substituting $O(0,0), A(1,0), B(0,1), C(1,1), D\left(x^{*}, y^{*}\right)$ into the expression of the sum, $\operatorname{det} J$ and $\operatorname{tr} J$, and obtaining the expression of the matrix determinant and trace corresponding to the equilibrium point formula, as shown in Table 4 .

(1) When $v(\Delta \pi)<0, a_{5}-b_{4}<0$, equilibrium point $D\left(x^{*}, y^{*}\right)$ does not exist; the steady state of each balance point is shown in Table 5 .

(2) When $b_{4}<a_{5}<-v(\Delta \pi)$, equilibrium point $D\left(x^{*}, y^{*}\right)$ does not exist, the steady state of each balance point is shown in Table 6 .

(3) When $\quad b_{4}>v(\Delta \pi) \geq 0$, equilibrium point $D\left(x^{*}, y^{*}\right)$ does not exist; the steady state of each balance point is shown in Table 7 . 
TABLe 4: Expressions of matrix determinants and traces corresponding to the equilibrium points of the replica dynamic system.

\begin{tabular}{lcc}
\hline Equilibrium point & $\operatorname{det} J$ & $\operatorname{tr} J$ \\
\hline$O(0,0)$ & $\left(a_{5}-b_{4}\right) v(\Delta \pi)$ & $a_{5}-b_{4}+v(\Delta \pi)$ \\
$A(1,0)$ & $-\left(a_{5}-b_{4}\right)\left[a_{5}+v(\Delta \pi)\right]$ & $b_{4}+v(\Delta \pi)$ \\
$B(0,1)$ & $b_{4} v(\Delta \pi)$ & $-b_{4}-v(\Delta \pi)$ \\
$C(1,1)$ & $-b_{4}\left[a_{5}+v(\Delta \pi)\right]$ & $b_{4}-\left[a_{5}+v(\Delta \pi)\right]$ \\
$D\left(x^{*}, y^{*}\right)$ & $\left(b_{4}\left[a_{5}+v(\Delta \pi)\right]\left(b_{4}-a_{5}\right) v(\Delta \pi)\right) / a_{5}^{2}$ & 0 \\
\hline
\end{tabular}

TABLE 5: Local stability of equilibrium points in case (1).

\begin{tabular}{lccc}
\hline Equilibrium point & $\operatorname{det} J$ & $\operatorname{tr} J$ & Stability \\
\hline$O(0,0)$ & + & - & Stable equilibrium \\
$A(1,0)$ & Uncertain & Uncertain & Saddle point \\
$B(0,1)$ & - & Uncertain & Saddle point \\
$C(1,1)$ & - & + & Unstable \\
\hline
\end{tabular}

TABLE 6: Local stability of equilibrium points in case (2).

\begin{tabular}{lccc}
\hline Equilibrium point & $\operatorname{det} J$ & $\operatorname{tr} J$ & Stability \\
\hline$O(0,0)$ & - & Uncertain & Saddle point \\
$A(1,0)$ & + & - & Stable equilibrium \\
$B(0,1)$ & - & + & Unstable \\
$C(1,1)$ & + & + & Unstable \\
\hline
\end{tabular}

TABLE 7: Local stability of equilibrium points in case (3).

\begin{tabular}{lccc}
\hline Equilibrium point & $\operatorname{det} J$ & $\operatorname{tr} J$ & Stability \\
\hline$O(0,0)$ & Uncertain & Uncertain & Saddle point \\
$A(1,0)$ & Uncertain & + & Saddle point \\
$B(0,1)$ & + & - & Stable equilibrium \\
$C(1,1)$ & - & Uncertain & Saddle point \\
\hline
\end{tabular}

Inference. When the construction cost of the prefabricated building is less than the gain from the construction unit's choice of the prefabricated building and the difference in the income from the choice of the traditional cast-in-place building, that is when $a_{4} \leq a_{2}+a_{3}-a_{1}$, construction units can continue to adopt prefabricated buildings without relying on government subsidies.

Proof. By Proposition 2, if $b_{4}>v(\Delta \pi) \geq 0$, the stable equilibrium of the system is (no incentive, adopt). Available $v(\Delta \pi) \geq 0$, deduced $\Delta \pi \geq 0$, came to a conclusion $a_{4} \leq a_{2}+a_{3}-a_{1}$.

According to Proposition 2 and inference, if the construction unit does not rely on government subsidies and continues to adopt prefabricated buildings, the government may consider the following measures:

(1) Control the price of traditional cast-in-place buildings, or consider the construction of traditional cast-in-place buildings. Environmental taxes are levied to appropriately limit the benefits of traditional cast-in-place construction units; (2) increase the popularization of low-carbon and environmentally-friendly publicity of fabricated buildings, so that more consumers can recognize the environmental benefits brought by fabricated buildings; and (3) the construction cost of the prefabricated building should be reduced in a targeted manner.

\section{Result Analysis}

According to the above analysis, the evolution process of the game under the different situations of the government and the construction unit can be obtained, as shown in Figures 1-3.

(1) As shown in Figure 1, when the perception of the construction unit is a loss, and if the subsidy cost paid by the government "incentive" is less than the "not adopted" by the construction unit, the government "does not incentive", which is when $v(\Delta \pi)<0, a_{5}-b_{4}<0$, the construction unit also "not applied." This situation reflects the current status of China's prefabricated buildings, that is, low consumer acceptance, lack of targeted government subsidies, and cannot effectively reduce the cost of prefabricated building construction. The construction unit has a negative attitude towards investing in the project and hates losses.

(2) As shown in Figure 2, when the perception of the construction unit is loss and the loss utility is greater than the government subsidy, the subsidy cost of the government incentive is greater than the construction unit does not "use" and obtain a fine which is when $b_{4}<a_{5}<-v(\Delta \pi)$ the government "incentives" and the construction unit also "does not apply." Under this circumstance, the construction unit adopts the perception of the prefabricated building as the loss, and the loss value is greater than the government incentive but does not use the fines paid, and the construction unit will not adopt it.

(3) As shown in Figure 3, when the perception of the construction unit is obtained and less than the government incentive, the penalty is not used, which is when $b_{4}>v(\Delta \pi) \geq 0$, the government "does not encourage," but the construction unit will "use." At this time, the construction unit adopts the cost of the assembled building, $a_{4} \leq a_{2}+a_{3}-a_{1}$. This kind of situation is the state that the government and the construction unit want to see together, and it is also the goal of our current efforts.

(4) The system does not reach (incentive, adopt) the stability of this state. It can be seen that in the long run, the current government subsidy policy cannot effectively stimulate the construction unit to adopt the prefabricated building. Targeting the construction cost of the prefabricated building is the correct way to promote the application of the construction unit. At the same time, moderately 


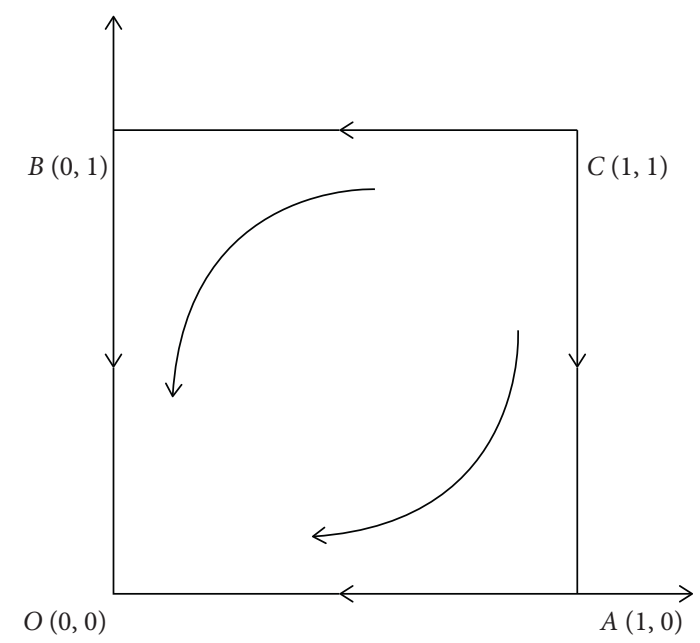

Figure 1: System evolution phase diagram for case (1).

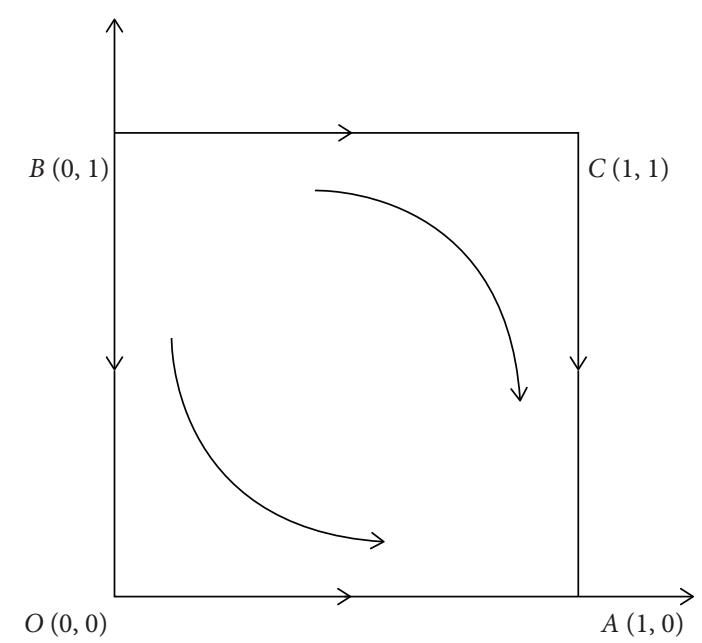

FIgURE 2: System evolution phase diagram for case (2).

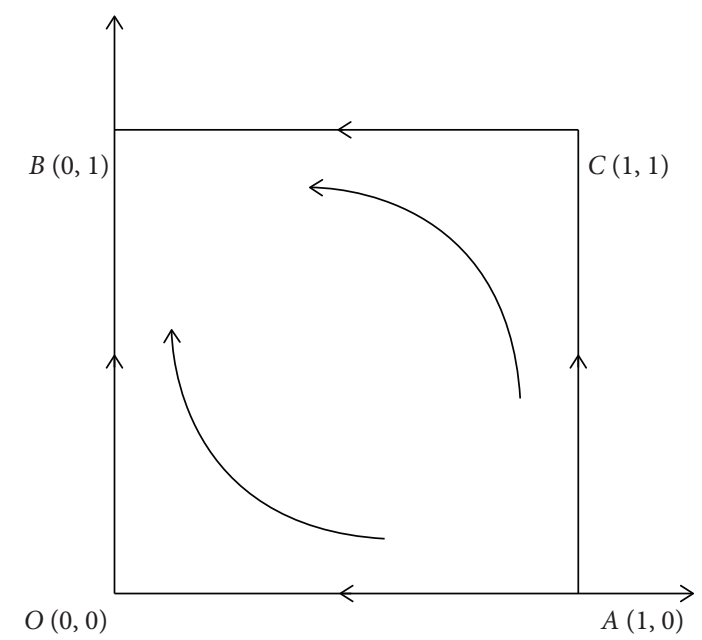

Figure 3: System evolution phase diagram for case (3).
TABLE 8: Related parameter assignment table.

\begin{tabular}{ccccccc}
\hline$a_{1}$ & $a_{2}$ & $a_{3}$ & $b_{1}$ & $\alpha$ & $\beta$ & $\lambda$ \\
\hline 3 & 5 & 1 & 2 & 0.88 & 0.88 & 2.25 \\
\hline
\end{tabular}

control the price of the traditional cast-in-place building, and levy an environmental tax on the traditional cast-in-place construction unit to control the traditional construction unit. Revenues, as well as increased environmental protection and low-carbon propaganda of fabricated buildings, can also promote the application of fabricated buildings.

\section{Numerical Simulation}

In order to explain the above propositions and conclusions more intuitively, this section uses numerical simulation to analyse. Assign the relevant parameters to Table 8 .

Get the conclusion as follows:

$$
v(\Delta \pi)= \begin{cases}\left(3-a_{4}\right)^{0.88}, & 3 \geq a_{4}>0, \\ -2.25\left(a_{4}-3\right)^{0.88}, & 3<a_{4} .\end{cases}
$$

Use MATLAB to draw as follows.

It can be seen from Figure 4 that under the condition that the income of the traditional building and the prefabricated building is certain, the perceived income of the construction unit gradually decreases with the increase of the construction cost of the prefabricated building, and the construction cost of the prefabricated building is obtained for the perception of the construction unit, or play a decisive role in the loss. When the cost of construction of a prefabricated building $0<a_{4} \leq 3$, the perception of the construction unit is obtained; when the construction cost of the prefabricated building $3<a_{4}$, the perception of the construction unit is loss.

Next, we analyse the decision-making interval of the construction unit in different situations. In Case (1), $v(\Delta \pi)$ $<0, a_{5}-b_{4}<0$; in Case (3), $b_{4}>v(\Delta \pi) \geq 0$. As shown in Figure 5, $b_{4}\left(a_{5}\right)=a_{5}, v\left(a_{4}\right)=\left\{\begin{array}{ll}\left(3-a_{4}\right)^{0.88}, & 3 \geq a_{4}>0 \\ -2.25\left(a_{4}-3\right)^{0.88}, & 3<a_{4}\end{array}\right.$, use MATLAB to draw as follows:

As shown in Figure 5, in Case (1), the stability interval of the strategy combination (not excited, not applied) is the interval II; in Case (3), the stability interval of the strategy combination (no incentive, application) is interval I. When the cost of construction of a prefabricated building $0<a_{4} \leq 3$, the perception of the construction unit $v\left(a_{4}\right) \geq 0$. At the same time, the subsidy cost $b_{4}$ paid by the government is greater than the perceived value of the construction unit $v\left(a_{4}\right)$, the government does not encourage, but the construction unit will adopt it. When the cost of construction of a prefabricated building $3<a_{4}<6$, the perception of the construction unit 


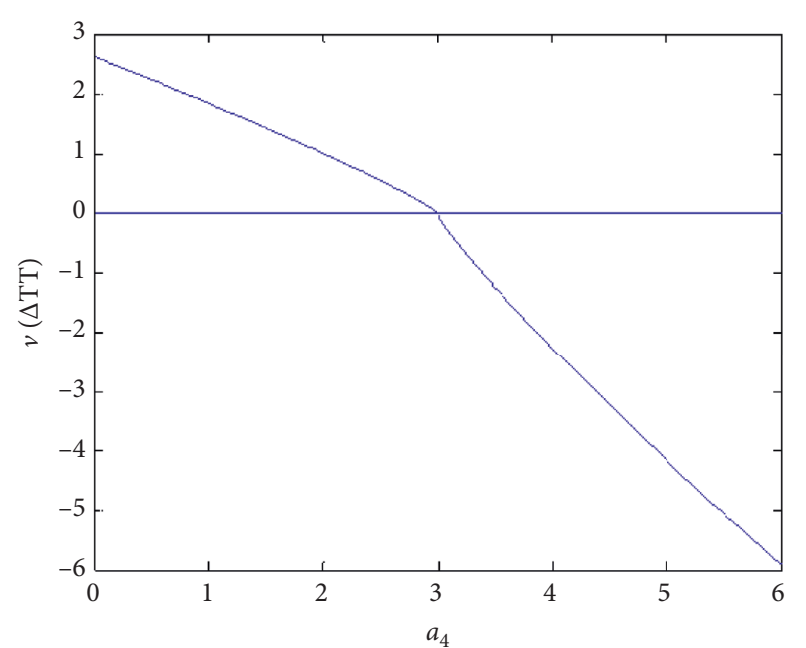

FIgURE 4: The impact of prefabricated building costs on the perceived value of the construction unit.

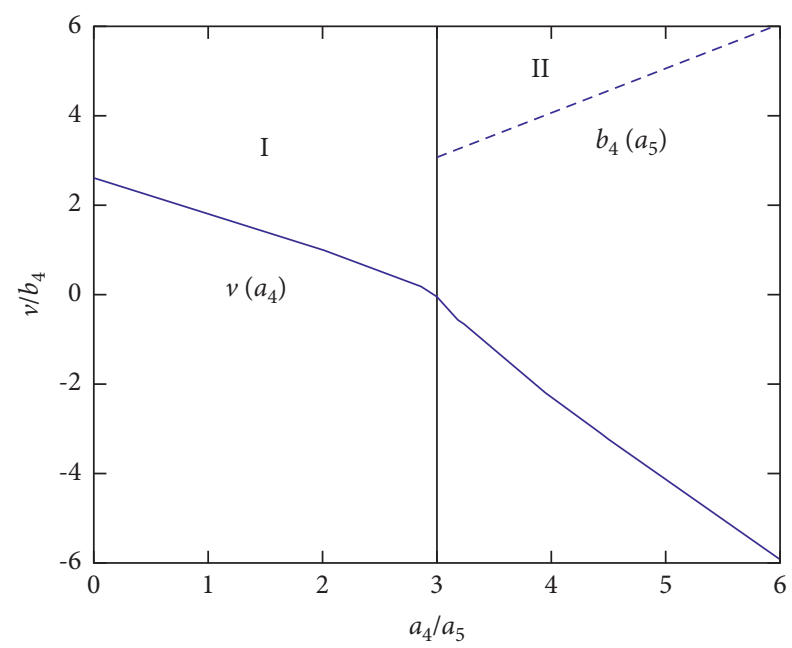

FIGURE 5: Schematic diagram of the corresponding interval of Cases (1) and (3).

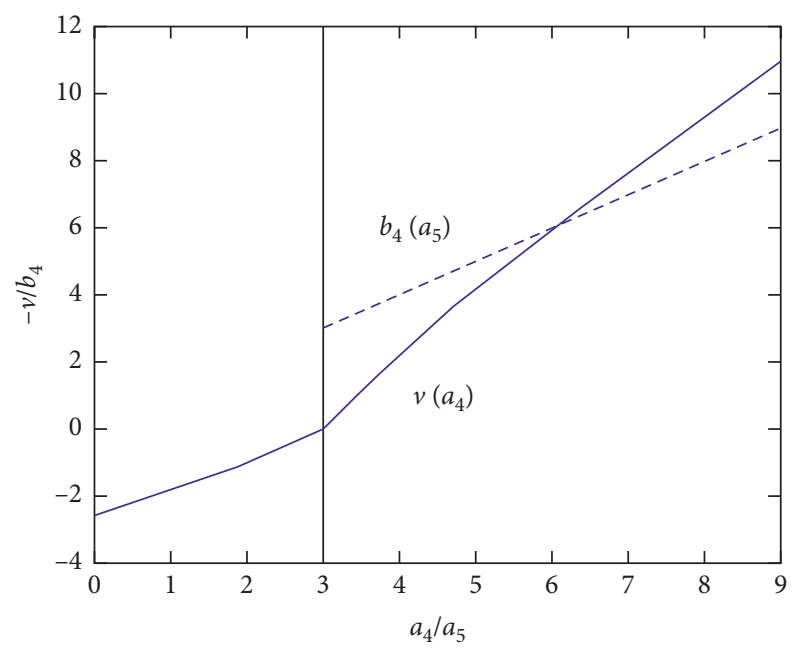

FIgURE 6: Schematic diagram of the corresponding interval of Cases (1) and (3). $v\left(a_{4}\right)<0$. At the same time, the subsidy cost paid $b_{4}$ by the government is greater than the perceived value of the construction unit, does not motivate the fine $a_{5}$, the government does not encourage and the construction unit does not adopt it.

As shown in Figure 6, in Case (2), the stability interval of the strategy combination (incentive, not applied) is interval $\mathrm{I}$, the perception of the construction unit $v\left(a_{4}\right)<0$. At the same time, the subsidy cost paid by the government $b_{4}$ is greater than the perceived value of the construction unit does not motivate the fine $a_{5}$, the government is motivated, but the construction unit does not apply.

In summary, moderately controlling the selling price of traditional cast-in-place buildings, levying environmental taxes on traditional cast-in-place construction units to control the income of traditional construction units and increasing the environmental protection of assembly buildings and the promotion of low-carbon energy can make. The perception of the construction unit is easier to obtain and has a certain promotion effect on the application of the prefabricated building; in the long run, the government subsidy cannot effectively promote the construction unit to continue to adopt the prefabricated building. It is the construction cost of the prefabricated building that determines whether or not the construction unit will use the prefabricated building. It is the construction cost of the prefabricated building that determines whether or not the construction unit will use the prefabricated building. Therefore, the government should focus on how to reduce the construction cost of prefabricated buildings in a targeted manner.

\section{Conclusions}

This paper introduces the foreground theory into the process of evolutionary game analysis, establishes the evolutionary game model of the government and the construction unit, uses the replication dynamic equation to analyse the strategic choice of the evolutionary game, and draws the following conclusions:

(1) There are only three stabilization strategies for the construction unit and the government's evolutionary game system, that is, the government does not encourage, the construction unit does not adopt; the government incentives, the construction unit does not adopt; the government does not encourage, the construction unit adopts.

(2) In the long run, government subsidies cannot determine whether the construction unit will adopt prefabricated buildings. The decisive factor is the construction cost of the prefabricated buildings. Therefore, the government's work should shift from subsidies to targeted reductions in the cost of prefabricated construction. The reward and punishment mechanism of government subsidies will also affect the decision-making of the construction unit, and the incentive and penalty amount should be determined according to the income obtained by the 
construction unit in traditional buildings and prefabricated buildings.

(3) If the construction unit does not rely on government subsidies and continues to adopt prefabricated buildings, the government may consider controlling the selling price of traditional cast-in-place buildings on the one hand, or levying environmental taxes on traditional cast-in-place construction units, and appropriately restricting traditional cast-in-place. The gains from the construction unit, on the other hand, increase the popularization of low-carbon, environmentally-friendly publicity of fabricated buildings, so that more consumers can recognize the environmental benefits brought by the assembled buildings.

The conclusion of this paper points out that the government's work should shift from subsidies to incentives for construction units to reduce the cost of prefabricated construction. The incentive process may involve information asymmetry, risk preference, and consumer factors. In particular, this paper does not consider the risk preference of the government and the construction unit, which will influence decisions in practice. This is the next step to be studied in this paper.

\section{Data Availability}

The data used to support the findings of this study are included within the article.

\section{Conflicts of Interest}

The authors declare that there are no conflicts of interest regarding the publication of this paper.

\section{Acknowledgments}

This work was supported by the National Natural Science Foundation of China (no. 71871150) and the Science and Technology Department of Sichuan Province Foundation (no. 2019JDR0148).

\section{References}

[1] Science and Technology and Industrialization Development Centre of the Ministry of Housing and Urban-Rural Construction, China Assembly Building Development Report, China Building Industry Press, Beijing, China, 2017.

[2] Central People's Government of the People's Republic of China, Opinions of the Central Committee of the Communist Party of China and the State Council on Further Strengthening the Management of Urban Planning and Construction, Vol. 2, Central People's Government of the People's Republic of China, Beijing, China, 2016.

[3] W. Cheng, X. Jiang, Q. Y. Yu, and H. Y. Fu, "Incremental cost estimation of prefabricated building engineering," Finance and Accounting Monthly, vol. 6, pp. 75-81, 2018.

[4] General Office of Beijing Municipal People's Government, Opinions of the General Office of the Beijing Municipal People's Government on Accelerating the Development of Assembled
Buildings, Vol. 2.22, General Office of Beijing Municipal People's Government, Beijing, China, 2017.

[5] General Office of the State Council, Guidelines for vigorously developing assembled buildings, General Office of the State Council, vol. 9, p. 27, Beijing, China, 2016.

[6] China Industrial Information Network, Development Survey, Future Development Trend and Prospect Analysis of China's Assembly Building Industry in 2019, Vol. 6.5, China Industrial Information Network, Beijing, China, 2019.

[7] W. G. Liu, Y. Tao, C. Mao, and P. P. Xu, "Textual and quantitative research on Chinese prefabricated construction policy from the perspective of policy tools," Journal of Chongqing University (Social Science Edition), vol. 134, no. 5, pp. 62-71, 2018.

[8] Z. Wang, B. Su, J. Coakley, and Z. Shen, "Prospect theory and IPO returns in China," Journal of Corporate Finance, vol. 48, pp. 726-751, 2018.

[9] W. B. Chen, L. N. Chen, and S. Q. Wang, "Investors' gambling behaviour-Ca perspective from profit/loss condition and investor sentiment," Chinese Journal of Management Science, vol. 27, no. 2, pp. 22-23, 2019.

[10] D. Kahneman and A. Tversky, "Prospect theory: an analysis of decision making under risk," Econometrica, vol. 47, no. 2, pp. 263-291, 1979.

[11] Z. G. Tao, Z. Y. Guang, S. Hao, and H. J. Song, "Multi-period closed-loop supply chain network equilibrium with carbon emission constraints," Resources, Conservation and Recycling, vol. 104, pp. 354-365, 2015.

[12] M. Talaei, B. Farhang Moghaddam, M. S. Pishvaee, A. Bozorgi-Amiri, and S. Gholamnejad, "A robust fuzzy optimization model for carbon-efficient closed-loop supply chain network design problem: a numerical illustration in electronics industry," Journal of Cleaner Production, vol. 113, pp. 662-673, 2016.

[13] S. Zhao, Q. Zhu, and L. Cui, "A decision-making model for remanufacturers: considering both consumers' environmental preference and the government subsidy policy," Resources, Conservation and Recycling, vol. 128, pp. 176-186, 2018.

[14] P. He, Y. He, and H. Xu, "Channel structure and pricing in a dual-channel closed-loop supply chain with government subsidy," International Journal of Production Economics, vol. 213, pp. 108-123, 2019.

[15] Y. L. Chen, S. Z. Lin, and Y. Z. Shi, "Evolutionary game on incentive policy for prefabrication," Journal of Civil Engineering and Management, vol. 35, no. 2, pp. 155-160, 2018.

[16] W. Chen and X. Hong, "Design of effective subsidy policy to develop green buildings: from the perspective of policy benefit," Clean Technologies and Environmental Policy, vol. 17, no. 4, pp. 1029-1038, 2015.

[17] H. Shen, P. Ying, and C. X. Guo, "Analysis of the evolution game of construction and demolition waste recycling behaviour based on prospect theory under environmental regulation," International Journal of Environmental Research \& Public Health, vol. 15, no. 7, pp. 1-17, 2018.

[18] L. Wang, Y.-M. Wang, and L. Martínez, "A group decision method based on prospect theory for emergency situations," Information Sciences, vol. 418, pp. 119-135, 2017.

[19] J. Polach and J. Kukacka, "Prospect theory in the heterogeneous agent model," Journal of Economic Interaction and Coordination, vol. 14, no. 1, pp. 147-174, 2019.

[20] P. Ren, Z. Xu, and Z. Hao, "Hesitant fuzzy thermodynamic method for emergency decision making based on prospect theory," IEEE Transactions on Cybernetics, vol. 47, no. 9, pp. 2531-2543, 2016. 
[21] R. Bouchouicha and F. M. Vieider, "Accommodating stake effects under prospect theory," Journal of Risk and Uncertainty, vol. 55, no. 1, pp. 1-28, 2017.

[22] Z. S. Chen, "Supply chain coordination with strategic consumer behaviour under the perspective of prospect theory," Journal of Industrial Engineering/Engineering Management, vol. 21, no. 4, pp. 93-100, 2017.

[23] Z. B. Zhao and Q. P. Man, "Evolutionary game anal y sis of risk management behaviour of major infrastructure projects based on prospect theory," Journal of Systems \& Management, vol. 1, pp. 109-117, 2018.

[24] T. Ning, X. P. Wang, and X. P. Hu, "Study on disruption management strategy of terminal logistics based on prospect theory," Systems Engineering-Theory \& Practice, vol. 39, no. 3, pp. 673-681, 2019.

[25] Y. He, P. He, F. Xu, and C. Shi, "Sustainable tourism modeling: pricing decisions and evolutionarily stable strategies for competitive tour operators," Tourism Economics, vol. 25, no. 5, pp. 779-799, 2019.

[26] P. He, Y. He, and F. Xu, "Evolutionary analysis of sustainable tourism," Annals of Tourism Research, vol. 69, pp. 76-89, 2018.

[27] R. Mahmoudi and M. Rasti-Barzoki, "Sustainable supply chains under government intervention with a real-world case study: an evolutionary game theoretic approach," Computers \& Industrial Engineering, vol. 116, pp. 130-143, 2018.

[28] H. Sun, Y. Wan, L. Zhang, and Z. Zhou, "Evolutionary game of the green investment in a two-echelon supply chain under a government subsidy mechanism," Journal of Cleaner Production, vol. 235, pp. 1315-1326, 2019.

[29] J. Quiggin, “A theory of anticipated utility," Journal of Economic Behavior \& Organization, vol. 3, no. 4, pp. 323-343, 1982.

[30] D. Schmeidler, "Subjective probability and expected utility without additivity," Econometrica, vol. 57, no. 3, pp. 571-587, 1989.

[31] M. E. Yaari, "The dual theory of choice under risk," Econometrica, vol. 55, no. 1, pp. 95-115, 1987.

[32] A. Tversky and D. Kahneman, "Advances in prospect theory: cumulative representation of uncertainty," Journal of Risk and Uncertainty, vol. 5, no. 4, pp. 297-323, 1992.

[33] Z. Q. Wang, Q. M. Zhang, and W. B. You, "An evolutionary game and simulation study on government incentive strategy of prefabricated buildings-from the perspective of government subsidy," Systems Engineering, vol. 3, pp. 151-158, 2019.

[34] J. W. Weibull, Evolutionary Game Theory, The MIT press, Cambridge, MA, USA, 1997.

[35] D. Friedman, "Evolutionary games in economics," Econometrica: Journal of the Econometric Society, vol. 59, pp. 637666, 1991. 